\title{
Animal Fat Intake Is Associated with Albuminuria in Patients with Non-Alcoholic Fatty Liver Disease and Metabolic Syndrome
}

\author{
Manuela Abbate 1,2 1 , Catalina M. Mascaró 1,2, Sofía Montemayor ${ }^{1,2}$, María Barbería-Latasa ${ }^{3}$, Miguel Casares ${ }^{4}$, \\ Cristina Gómez ${ }^{5}$, Lucia Ugarriza ${ }^{1,2,6}$, Silvia Tejada ${ }^{1,2,7}$ (D) Itziar Abete ${ }^{7,8}$ (D), María Ángeles Zulet ${ }^{7,8}$ (D), \\ Antoni Sureda $1,2,7$, J. Alfredo Martínez ${ }^{7,8,9}$ (D) and Josep A. Tur 1,2,7,*(D)
}

Citation: Abbate, M.; Mascaró, C.M. Montemayor, S.; Barbería-Latasa, M.; Casares, M.; Gómez, C.; Ugarriza, L.; Tejada, S.; Abete, I.; Zulet, M.Á.; et al. Animal Fat Intake Is Associated with Albuminuria in Patients with Non-Alcoholic Fatty Liver Disease and Metabolic Syndrome. Nutrients 2021, 13, 1548. https://doi.org/ $10.3390 /$ nu13051548

Academic Editor: Henricus A. M. Mutsaers

Received: 9 April 2021

Accepted: 29 April 2021

Published: 4 May 2021

Publisher's Note: MDPI stays neutral with regard to jurisdictional claims in published maps and institutional affiliations.

Copyright: (c) 2021 by the authors. Licensee MDPI, Basel, Switzerland. This article is an open access article distributed under the terms and conditions of the Creative Commons Attribution (CC BY) license (https:/ / creativecommons.org/licenses/by/ $4.0 /)$.
1 Research Group in Community Nutrition and Oxidative Stress, University of the Balearic Islands-IUNICS, 07122 Palma de Mallorca, Spain; manuela.abbate@uib.es (M.A.); c.mascaro@uib.es (C.M.M.); sofia.montemayor@uib.es (S.M.); luciaugarriza@gmail.com (L.U.); silvia.tejada@uib.es (S.T.); antoni.sureda@uib.es (A.S.)

2 Health Research Institute of Balearic Islands (IdISBa), 07120 Palma de Mallorca, Spain

3 Department of Preventive Medicine and Public Health, University of Navarra, 31008 Pamplona, Spain; mbarberia.3@unav.es

4 Radiodiagnostics Service, Red Asistencial Juaneda, 07011 Palma de Mallorca, Spain; casaresmiguel@gmail.com

5 Clinical Analysis Service, University Hospital Son Espases, 07120 Palma de Mallorca, Spain; cristina.gomez@ssib.es

6 Camp Redó Primary Health Care Centre, 07010 Palma de Mallorca, Spain

7 CIBER Physiopathology of Obesity and Nutrition (CIBEROBN), Instituto de Salud Carlos III (ISCIII), 28029 Madrid, Spain; iabetego@unav.es (I.A.); mazulet@unav.es (M.Á.Z.); jalfredo.martinez@imdea.org (J.A.M.)

8 Department of Nutrition, Food Sciences and Physiology, Center for Nutrition Research, University of Navarra, IDISNA, 31008 Pamplona, Spain

9 Cardiometabolic Precision Nutrition Program, IMDEA Food, CEI UAM-CSIC, 28049 Madrid, Spain

* Correspondence: pep.tur@uib.es

Abstract: Non-alcoholic fatty liver disease (NAFLD) and metabolic syndrome (MetS) are associated with chronic kidney disease (CKD). Diet could play a predisposing role in the development of increased albuminuria in patients with NAFLD and MetS; however, published evidence is still limited. The aim of this cross-sectional analysis was to assess whether dietary fats are associated with changes in urinary albumin-to-creatinine ratio (UACR) in 146 patients aged 40-60-years with NAFLD and MetS. Dietary data were collected by food frequency questionnaire; UACR was measured in a single first morning void. Sources and types of dietary fats used in the analysis were total fat, fats from animal and vegetable sources, saturated, monounsaturated, polyunsaturated, and trans fats. One-way analysis of variance was performed to assess differences in dietary fats intakes across stages of UACR. The association between dietary fats and UACR was assessed by Pearson's correlation coefficient and multivariable linear regression. Patients with increased UACR showed a worse cardiometabolic profile and higher intakes of animal fat, as compared to patients with normal levels of albuminuria. Animal fat intake was associated with mean UACR, independent of potential covariates.

Keywords: dietary intake; animal fat; NAFLD; metabolic syndrome; albuminuria; albumin-tocreatinine ratio

\section{Introduction}

Increased albuminuria, defined as urine albumin-to-creatinine ratio (UACR) $\geq$ 30-300 mg/g [1], is a well-established early marker of chronic kidney disease (CKD) and a risk factor for cardiovascular disease (CVD) and cardiovascular mortality as well as 
all-cause mortality in patients with metabolic syndrome (MetS) [2-5]. Importantly, recent evidence from population-based studies shows that even within the conventional normal range, albuminuria is associated with MetS and cardiovascular risk factors in the general population $[3,4,6,7]$, and that it can independently predict kidney disease progression in individuals with and without diabetes [8].

Non-alcoholic fatty liver disease (NAFLD) is the hepatic manifestation of the MetS, and is also an independent risk factor for CKD, CVD, cardiovascular mortality, and all-cause mortality [9-12]. Moreover, patients with NAFLD are more likely to have higher levels of albuminuria as compared to patients without [13-15]. The manifestation of increased albuminuria in NAFLD can possibly worsen the pathophysiology of CKD and CVD even further, making this population at particular risk.

Unhealthy lifestyle factors may influence the development of albuminuria; however, studies are very limited. In general, poor diet quality, sedentary lifestyle, and obesity have been associated with an increased risk of developing increased albuminuria in participants with normal renal function [16-19]. On the other hand, weight loss could reduce increased UACR and proteinuria in patients with T2DM and MetS, possibly helped by improved insulin sensitivity, blood pressure, and serum lipid profile [20-22].

Studies looking at specific nutrients have mainly focused on proteins and shown that a high intake might contribute to kidney dysfunction in T2DM patients as well as in the general population [23-27]. Increased intakes of proteins from animal sources seem to be more strongly associated with a worse renal outcome as compared with proteins from plants [19,28]; however, such findings have not always been confirmed, with some studies arguing that the total quantity of proteins, rather than their source, is more likely to affect renal health $[28,29]$. Despite the important role that diet might play in both the prevention and the possible amelioration of albuminuria, evidence is still limited, and more studies are needed.

An important gap in research exists about the role of dietary fats on albuminuria in patients with MetS. In the general population, saturated fats, hence fats from animal sources, have been associated with high levels of albuminuria [30,31]; however, it is unknown whether this association exists in patients with MetS and NAFLD.

The aim of this study is to assess the role of dietary fats intakes on albuminuria in patients with NAFLD and the MetS.

\section{Materials and Methods}

\subsection{Study Design}

The present study is a cross-sectional analysis that uses data from an ongoing multicenter prospective randomized controlled trial on the effects of a customized dietary and physical activity intervention on changes in liver fat deposits over a period of 24 months. The study is carried out by the Research group on Community Nutrition and Oxidative Stress of the University of the Balearic Islands and the Department of Food Science and Physiology of the Faculty of Pharmacy and Nutrition of the University of Navarra, Spain. Baseline data used in the present analysis were collected between October 2017 and November 2019.

\subsection{Subjects}

The present cross-sectional analysis includes 146 patients with a diagnosis of NAFLD by liver ultrasound, aged between 40 and 60 years, with a body mass index (BMI) between 27 and $40 \mathrm{~kg} / \mathrm{m}^{2}$, and suffering from the MetS, as presenting at least three of the main MetS traits as described in the International Diabetes Federation (IDF) consensus [32]: (1) BMI $>30 \mathrm{~kg} / \mathrm{m}^{2}$ or increased waist circumference: $\geq 94 \mathrm{~cm}$ in males and $\geq 80 \mathrm{~cm}$ in females; (2) triglycerides (TG) levels $\geq 150 \mathrm{mg} / \mathrm{dL}$ (1.7 mmol/L) or specific treatment; (3) reduced HDL cholesterol: $<40 \mathrm{mg} / \mathrm{dL}(1.03 \mathrm{mmol} / \mathrm{L})$ in males and $<50 \mathrm{mg} / \mathrm{dL}$ $(1.29 \mathrm{mmol} / \mathrm{L})$ in females or specific treatment; (4) raised blood pressure (BP): systolic $\mathrm{BP} \geq 130$ or diastolic $\mathrm{BP} \geq 85 \mathrm{~mm} \mathrm{Hg}$ or treatment of previously diagnosed hyperten- 
sion; (5) raised fasting plasma glucose (FPG) $\geq 100 \mathrm{mg} / \mathrm{dL}$ (5.6 mmol/L) or previously diagnosed type 2 diabetes.

Participants were excluded when they had the following exclusion criteria: documented history of previous cardiovascular disease; documented history of previous liver disease with the exception of NAFLD; concomitant or previous (within 5 years) malignant tumor; previous surgical procedure for weight loss (bariatric surgery); acute febrile illness; concomitant urinary tract infection or post renal hematuria; hemochromatosis; severe/nephrotic-range albuminuria; non-medicated depression and anxiety; chronic abuse of drugs or alcohol; obesity associated with endocrine disease (except medicated hypothyroidism); treatment with steroids; intense physical exercise; pregnancy; unwillingness to provide informed consent.

\subsection{Ethics}

The Ethics Committee of the Balearic Islands (ref. IB 2251/14 PI) and the Ethics Committee of the University of Navarra (ref. 054/2015mod2) approved this trial, which followed the Declaration of Helsinki. All participants were informed of the study and signed a written consent. This study was recorded at ClinicalTrials.gov (number NCT04442620; https:/ / clinicaltrials.gov/ct2/show/NCT04442620; accessed on 14 February 2021).

\subsection{Anthropometrics and Blood Pressure}

Height, body weight, BMI, and waist circumference (WC) were collected by trained dietitians. Height was measured by the nearest millimeter using a mobile stadiometer (Seca 213, SECA Deutschland, Hamburg, Germany) with the patient's head positioned parallel to the soil (along the horizontal Frankfort plane). Weight was measured using the Tanita MC780P-MA digital segmental body composition analyzer (Tanita, Tokyo, Japan), with the patient wearing light clothes (for which $0.6 \mathrm{~kg}$ was subtracted from the total), and bare feet. BMI was calculated by dividing the weight in $\mathrm{kg}$ by the square of the height in $\mathrm{cm}$. WC was measured using a measurement tape with the patient standing upright. The measurement was taken in duplicate, and the average of the two measurements was used for analysis. Blood pressure (BP) was measured in the non-dominant arm, with the patient resting in a seated position, using a validated semi-automatic oscillometer (Omron HEM-705CP, Hoofddorp, The Netherlands). The measurement was taken in triplicate, 2 min apart, and the average of the three measurements was used for analysis.

\subsection{General Data and Medical History}

Information on socioeconomics, medical history, use of medication, previous diseases, and smoking habits were obtained from all participants. As for alcohol consumption, participants were asked the average weekly consumption of alcoholic beverages and given the option to answer as either "none", " $<7$ ", or " $\geq 7$ ". Those patients who were consuming more than 7 alcoholic beverages a week were excluded if presenting a recorded history of alcohol abuse or if considered to present a drinking problem by their primary healthcare physician. Leisure time physical activity over the previous 12 months was also recorded by means of the validated Spanish version of the Minnesota Leisure Time. Physical activity was expressed as metabolic equivalents of tasks per hour (MET/h) [33,34].

\subsection{Total Energy and Dietary Fats Intake}

Total energy expressed as Kcal per day (Kcal/d), total fat, fats from animal and vegetable sources, saturated fatty acids (SFA), monounsaturated fatty acids (MUFA), polyunsaturated fatty acids (PUFA), and trans fatty acids (TFA), expressed as grams per day (g/d), were derived from the analysis of a validated Food Frequency Questionnaire consisting of 148 food and drink items (148 items-FFQ) [35], which assesses dietary intakes over the previous 12 months. 


\subsection{Blood Collection and Analysis}

Venous blood samples from all participants were collected after a $12 \mathrm{~h}$ night-time fast in one EDTA sample tube for plasma and one citrate sample tube for serum and centrifugated at $3000 \mathrm{rpm}$ for $10 \mathrm{~min}$. Samples were analyzed for fasting glycemia, glycated hemoglobin (HbA1c), bilirubin, aspartate aminotransferase (AST), alanine aminotransferase (ALT), gamma-glutamyl transferase (GGT), uric acid, urea, creatinine, albumin, total cholesterol, high-density lipoprotein cholesterol (HDL-C), triglycerides (TG), and C-reactive protein (CRP) on the Abbott ARCHITECT c16000 (Abbott Laboratories, Abbott Park, IL, USA), employing specific commercial kits. Low-density lipoprotein cholesterol (HDL-C) was calculated by using the Friedewald Formula [36]. Serum fasting insulin was assayed on the Cobas e411 automated analyzer (Roche, Switzerland), or on the Triturus autoanalyzer (Grifols, Barcelona, Spain), depending on the recruiting center, using either an enzyme-based electrochemiluminescence assay or an enzyme-linked immunosorbent assay kit. A single spot urine specimen collected in the early morning was requested to each participant to measure urinary albumin and creatinine excretion. Urine albumin concentration was determined by immunoturbidimetric assay and urine creatinine by a modified Jaffe method on an Abbott ARCHI-TECT c16000. Urine albumin-to-creatinine ratio (UACR) was expressed as $\mathrm{mg} / \mathrm{g}$. Normal albuminuria was defined as UACR $<10 \mathrm{mg} / \mathrm{g}$, mildly increased albuminuria was defined as UACR $\geq 10-29 \mathrm{mg} / \mathrm{g}$, and moderately increased albuminuria was defined as $\geq 30-300 \mathrm{mg} / \mathrm{g}$.

Insulin resistance index was calculated using the Homeostatic Model Assessment for Insulin Resistance (HOMA-IR) formula by Matthews et al. [37]; estimated GFR (eGFR) was calculated using the Chronic Kidney Disease Epidemiology Collaboration (CKD-EPI) formulas [38] and expressed as $\mathrm{mL} / \mathrm{min} / 1.73 \mathrm{~m}^{2}$.

\subsection{Statistical Analyses}

Statistical analyses were carried out using the SPSS statistical software package version 25.0 (SPSS Inc., Chicago, IL, USA). Continuous variables were expressed as means \pm standard deviation (SD), and categorical variables were expressed as frequencies. Assumption of normality for continuous variables was assessed with the Shapiro-Wilk test and visual inspection of histograms and normal probability plots.

One-way analysis of variance (ANOVA) (equal variance) or Welch's $t$-test (unequal variance) for continuous variables and $\chi^{2}$ test for categorical variables, were used to compare unadjusted means and frequencies of clinical characteristics and dietary intakes of patients stratified by UACR status (normal, mildly, and moderately increased). The Bonferroni test was used for post hoc analyses.

Linear associations between variables were evaluated by Pearson's correlation coefficient. Covariates with a level of significance $(p)$ below 0.05 (two-tailed) were entered in multiple linear regression models to investigate their association with UACR.

Multivariable regression analyses were carried out separately according to type of fat exposure (source of fat: animal and vegetable; type of fat: MUFA, PUFA, SFA, and TFA), adjusted for energy intakes (Kcal/d). Significant models were then further adjusted for gender (male/female), age (years, continuous variable), smoking (yes/no), alcohol consumption over $20 \mathrm{~g} / \mathrm{d}$ (yes/no), and physical activity (MET/h, continuous variable).

All $p$-values were two-sided, with $p<0.05$.

\section{Results}

Of the 146 patients with ultrasound proven NAFLD and MetS included in the analysis, 58 were women $(39.7 \%), 24(16.4 \%)$ were current smokers, and $25(17.1 \%)$ were consuming more than $20 \mathrm{~g}$ of alcohol a day. Mean \pm SD age was $52 \pm 7$, and mean BMI was $33.71 \pm 3.72$; $102(69.9 \%)$ patients presented normal levels, $24(16.4 \%)$ mildly increased levels, and 20 $(13.7 \%)$ increased levels of albuminuria. The prevalence of T2DM was $21.2 \%(n=31)$, and of high BP was $34.9 \%(n=51)$. 
Characteristics of the study cohort as stratified by UACR status are displayed in Table 1. As compared to patients with normal levels of albuminuria, patients with UACR $30-300 \mathrm{mg} / \mathrm{g}$ presented a higher diastolic $\mathrm{BP}$, and higher levels of fasting glucose, $\mathrm{HbA} 1 \mathrm{c}$, and HOMA-IR than patients with normal albuminuria. They were also more likely to be male and present higher serum creatine levels than patient with mildly increased albuminuria. Finally, patients with mildly increased albuminuria presented a higher eGFR than those with normal albuminuria. There were no significant differences across UACR status for age, smoking status, alcohol consumption, waist and hip circumferences, body weight, BMI, systolic BP, heart rate, total-cholesterol, HDL-C and LDL-C, TG, prevalence of T2DM, high BP, physical activity levels (expressed as MET/h), and use of medications.

Table 1. Differences in patients' characteristics across stages of UACR.

\begin{tabular}{|c|c|c|c|c|c|}
\hline$n$ & $\begin{array}{c}\text { UACR }<10 \mathrm{mg} / \mathrm{g} \\
102\end{array}$ & UACR $\geq \underset{24}{10-29 \mathrm{mg} / \mathrm{g}}$ & $\begin{array}{c}\text { UACR } 30-300 \mathrm{mg} / \mathrm{g} \\
20\end{array}$ & $p^{*}$ & Post Hoc \\
\hline Age (y) & $52.58 \pm 8.03$ & $51.17 \pm 6.10$ & $52.80 \pm 6.07$ & 0.690 & \\
\hline Gender $[n(\%)]$ & & & & 0.010 & \\
\hline Females & $41(40.2)$ & $14(58.3)$ & $3(15.0)$ & & $b>c$ \\
\hline Males & $61(59.8)$ & $10(41.7)$ & $17(85.0)$ & & $c>b$ \\
\hline Alcohol $(\geq 20 \mathrm{~g} / \mathrm{d})[n(\%)]$ & $20(19.6)$ & $3(12.5)$ & $2(10.0)$ & 0.450 & \\
\hline Currently smoking $[n(\%)]$ & $18(17.6)$ & $3(12.5)$ & $3(15.0)$ & 0.820 & \\
\hline Waist circumference $(\mathrm{cm})$ & $111.02 \pm 8.74$ & $112.08 \pm 9.61$ & $115.79 \pm 10.21$ & 0.100 & \\
\hline Weight $(\mathrm{kg})$ & $94.21 \pm 13.04$ & $94.84 \pm 14.62$ & $100.62 \pm 15.75$ & 0.160 & \\
\hline BMI $\left(\mathrm{kg} / \mathrm{m}^{2}\right)$ & $33.27 \pm 3.58$ & $34.58 \pm 3.35$ & $34.82 \pm 4.47$ & 0.110 & \\
\hline Systolic BP (mm Hg) & $133.56 \pm 13.68$ & $135.90 \pm 15.13$ & $141.06 \pm 16.97$ & 0.100 & \\
\hline Diastolic BP (mm Hg) & $83.88 \pm 8.60$ & $86.15 \pm 9.78$ & $89.73 \pm 10.47$ & 0.030 & $c>a$ \\
\hline Physical activity (MET/h) & $20.36 \pm 19.48$ & $18.28 \pm 19.55$ & $14.06 \pm 14.35$ & 0.400 & \\
\hline Fasting glucose (mg/dL) & $109.03 \pm 25.49$ & $123.83 \pm 57.87$ & $148.35 \pm 83.04$ & 0.001 & $c>a$ \\
\hline $\mathrm{HbA} 1 \mathrm{c}(\%)$ & $5.93 \pm 0.85$ & $6.19 \pm 1.46$ & $6.99 \pm 2.54$ & 0.005 & $c>a$ \\
\hline HOMA-IR & $5.20 \pm 3.10$ & $6.80 \pm 3.64$ & $9.61 \pm 9.53$ & 0.040 & $c>a$ \\
\hline Total cholesterol (mg/dL) & $197.73 \pm 44.30$ & $196.63 \pm 33.24$ & $195.35 \pm 36.36$ & 0.970 & \\
\hline HDL cholesterol (mg/dL) & $44.74 \pm 11.01$ & $43.59 \pm 7.14$ & $42.31 \pm 10.34$ & 0.600 & \\
\hline LDL cholesterol (mg/dL) & $118.72 \pm 35.90$ & $114.74 \pm 27.16$ & $106.34 \pm 31.28$ & 0.340 & \\
\hline Triglycerides (mg/dL) & $175.43 \pm 125.54$ & $191.50 \pm 115.09$ & $239.20 \pm 149.50$ & 0.130 & \\
\hline AST $(\mathrm{U} / \mathrm{L})$ & $25.81 \pm 13.28$ & $23.83 \pm 9.87$ & $30.06 \pm 15.52$ & 0.300 & \\
\hline $\operatorname{ALT}(\mathrm{U} / \mathrm{L})$ & $35.85 \pm 30.98$ & $35.67 \pm 25.40$ & $44.85 \pm 34.22$ & 0.470 & \\
\hline GGT $(\mathrm{U} / \mathrm{L})$ & $50.37 \pm 63.77$ & $49.29 \pm 22.29$ & $49.05 \pm 30.88$ & 0.990 & \\
\hline Serum creatinine (mg/dL) & $0.84 \pm 0.15$ & $0.77 \pm 0.14$ & $0.92 \pm 0.19$ & 0.005 & $c>b$ \\
\hline $\mathrm{eGFR}\left(\mathrm{ml} / \mathrm{min} / 1.73 \mathrm{~m}^{2}\right)$ & $85.99 \pm 19.28$ & $97.50 \pm 14.47$ & $83.78 \pm 23.09$ & 0.010 & $b>a$ \\
\hline $\operatorname{HBP}[n(\%)]$ & $36(35.3)$ & $6(25.0)$ & $9(45.0)$ & 0.380 & \\
\hline $\mathrm{T} 2 \mathrm{DM}[n(\%)]$ & $21(20.6)$ & $5(20.8)$ & $5(25.0)$ & 0.910 & \\
\hline $\begin{array}{l}\text { Use of hypoglycemic agents (any) }[n \\
(\%)]\end{array}$ & $20(19.6)$ & $4(16.7)$ & $5(25.0)$ & 0.783 & \\
\hline Oral hypoglycemic agents alone & $19(18.6)$ & $3(12.5)$ & $4(20.0)$ & 0.750 & \\
\hline Insulin and oral hypoglycemic agents & $1(1.0)$ & $1(4.2)$ & $1(5.0)$ & 0.372 & \\
\hline Antihypertensive agents (any) $[n(\%)]$ & $36(35.3)$ & $6(25.0)$ & $9(45.0)$ & 0.379 & \\
\hline Diuretic & $9(8.8)$ & $3(12.5)$ & $4(20.0)$ & 0.331 & \\
\hline$\beta$-Blocker & $6(5.9)$ & $0(0.0)$ & $2(10.0)$ & 0.331 & \\
\hline Calcium-channel blockers & $5(4.9)$ & $0(0.0)$ & $3(15.0)$ & 0.084 & \\
\hline $\mathrm{ACEi} / \mathrm{ARBs}$ & $31(30.4)$ & $6(25.0)$ & $9(45.0)$ & 0.330 & \\
\hline Lipid-lowering agents (any) $[n(\%)]$ & $29(28.4)$ & $4(16.7)$ & $5(25.0)$ & 0.494 & \\
\hline Statin alone & $20(19.6)$ & $4(16.7)$ & $3(15.0)$ & 0.861 & \\
\hline Fibrate alone & $7(6.9)$ & $0(0.0)$ & $1(5.0)$ & 0.411 & \\
\hline Statin and fibrate & $2(2.0)$ & $0(0.0)$ & $1(5.0)$ & 0.504 & \\
\hline
\end{tabular}

Abbreviations: ACEi: angiotensin converting enzyme inhibitors; ALT: alanine aminotransferase; AST: aspartate aminotransferase; ARBs: angiotensin II receptor blockers; BMI: body mass index; BP: blood pressure; eGFR: estimated glomerular filtration rate; GGT: gammaglutamyl transferase; HbA1c: glycated hemoglobin; HBP: high blood pressure; HDL cholesterol: high-density lipoprotein cholesterol; HOMA-IR: Homeostatic Model Assessment for Insulin Resistance; LDL cholesterol: low-density lipoprotein cholesterol; METs: metabolic equivalents; T2DM: type 2 diabetes mellitus; UACR: urine albumin-to-creatinine ratio. Data are presented as mean \pm standard deviation or counts $(\%)$. * $p$ obtained by one-way ANOVA (equal variance) or Welch's $t$-test (unequal variance) for continuous variables and $\chi^{2}$ test for categorical variables. Post hoc test by Bonferroni: $\mathrm{a}=\mathrm{UACR}<10 \mathrm{mg} / \mathrm{g}$ group; $\mathrm{b}=\mathrm{UACR} \geq 10-29 \mathrm{mg} / \mathrm{g}$ group; $\mathrm{c}=\mathrm{UACR} \geq$ $30-300 \mathrm{mg} / \mathrm{g}$ group. 
In terms of total energy and dietary fats intakes, as displayed in Table 2, patients with moderately increased albuminuria presented higher intakes of animal fat than those with normal albuminuria. No other significant differences were found across the three groups.

Table 2. Difference in fat intakes across stages of UACR.

\begin{tabular}{|c|c|c|c|c|c|}
\hline $\begin{array}{c}\text { Mean Daily Intakes } \\
n\end{array}$ & $\begin{array}{c}\text { UACR }<10 \mathrm{mg} / \mathrm{g} \\
102\end{array}$ & $\begin{array}{c}\text { UACR } \geq \underset{24}{10-29} \mathrm{mg} / \mathrm{g} \\
24\end{array}$ & $\begin{array}{c}\text { UACR } \geq 30-300 \mathrm{mg} / \mathrm{g} \\
20\end{array}$ & $p^{*}$ & Post Hoc \\
\hline Total Energy (Kcal) & $2458.92 \pm 840.92$ & $2334.95 \pm 533.24$ & $2720.89 \pm 978.34$ & 0.300 & \\
\hline Total fat $(\mathrm{g})$ & $103.75 \pm 37.69$ & $106.88 \pm 39.37$ & $116.77 \pm 39.03$ & 0.400 & \\
\hline Animal fat (g) & $49.35 \pm 21.51$ & $47.49 \pm 20.30$ & $66.70 \pm 31.80$ & 0.030 & $c>a$ \\
\hline Vegetable fat (g) & $59.79 \pm 27.14$ & $65.36 \pm 30.76$ & $72.98 \pm 32.67$ & 0.280 & \\
\hline MUFA (g) & $49.76 \pm 19.68$ & $53.40 \pm 19.86$ & $55.55 \pm 18.10$ & 0.420 & \\
\hline PUFA (g) & $16.68 \pm 6.37$ & $17.68 \pm 12.10$ & $17.48 \pm 7.96$ & 0.820 & \\
\hline SFA (g) & $28.82 \pm 12.28$ & $28.63 \pm 10.63$ & $35.03 \pm 14.00$ & 0.120 & \\
\hline TFA (g) & $0.75 \pm 0.47$ & $0.90 \pm 0.64$ & $0.97 \pm 0.51$ & 0.130 & \\
\hline
\end{tabular}

Abbreviations: MUFA: monounsaturated fatty acids; PUFA: polyunsaturated fatty acids; SFA: saturated fatty acids; TFA: trans fatty acids; UACR: urine albumin-to-creatinine ratio. Data are presented as mean \pm standard deviation. ${ }^{*} p$ obtained by one-way ANOVA (equal variance) or Welch's $t$-test (unequal variance). Post hoc test by Bonferroni: a $=\mathrm{UACR}<10 \mathrm{mg} / \mathrm{g}$ group; $\mathrm{c}=\mathrm{UACR} \geq 30-300 \mathrm{mg} / \mathrm{g}$ group.

As shown in Table 3 and Figure 1, Pearson's correlation analysis suggested that UACR was significantly correlated with total energy, total fat, fat from animal sources, fat from vegetables sources, PUFA, SFA, and TFA (all $p>0.05$ ). Multivariable regression analyses showed that animal fat was the only significant predictor of UACR increase, independently of total caloric intake $\left(S \beta C\right.$ (standardized $\beta$-coefficient) $=0.41, p=0.013 ; R^{2}=0.159$, $p=0.001$ ). When the model was adjusted for gender, age, smoking status, alcohol consumption, physical activity, and treatment with angiotensin converting enzyme inhibitors (ACEi) or angiotensin II receptor blockers (ARBs), animal fat remained significantly associated with increased UACR $\left(S \beta C=0.43, p=0.013 ; R^{2}=0.202, p=0.020\right)$.

Table 3. Correlation and multivariable analyses of the relationship between UACR (mg/g) and energy and dietary fats.

\begin{tabular}{|c|c|c|c|c|c|c|}
\hline & \multicolumn{2}{|c|}{ Correlation Analysis } & \multicolumn{2}{|c|}{ Multivariable Analysis (1) } & \multicolumn{2}{|c|}{ Multivariable Analysis (2) } \\
\hline & $r$ & $p$ & $S \beta C$ & $p$ & $S \beta C$ & $p$ \\
\hline Total energy (Kcal/d) & 0.21 & 0.012 & -0.11 & 0.61 & 0.03 & 0.88 \\
\hline Total fat $(\mathrm{g} / \mathrm{d})$ & 0.20 & 0.017 & & & & \\
\hline Animal fat $(\mathrm{g} / \mathrm{d})$ & 0.39 & $<0.001$ & 0.41 & 0.013 & & \\
\hline Vegetable fat $(\mathrm{g} / \mathrm{d})$ & 0.24 & 0.018 & 0.15 & 0.31 & & \\
\hline MUFA (g/d) & 0.12 & 0.16 & & & & \\
\hline PUFA (g/d) & 0.18 & 0.04 & & & 0.04 & 0.68 \\
\hline $\mathrm{SFA}(\mathrm{g} / \mathrm{d})$ & 0.25 & 0.003 & & & 0.16 & 0.47 \\
\hline TFA $(\mathrm{g} / \mathrm{d})$ & 0.20 & 0.02 & & & 0.06 & 0.65 \\
\hline
\end{tabular}

Abbreviations: MUFA: monounsaturated fatty acids; PUFA: polyunsaturated fatty acids; SFA: saturated fatty acids; TFA: trans fatty acids; $S \beta C$ : standardized $\beta$-coefficient. (1): multivariable model including energy, fat from animal sources and fat from vegetable sources as predictors, $R^{2}=0.159, p=0.001$; (2): multivariable model including energy, PUFA, SFA, and TFA as predictors, $R^{2}=0.064, p=0.061$. 

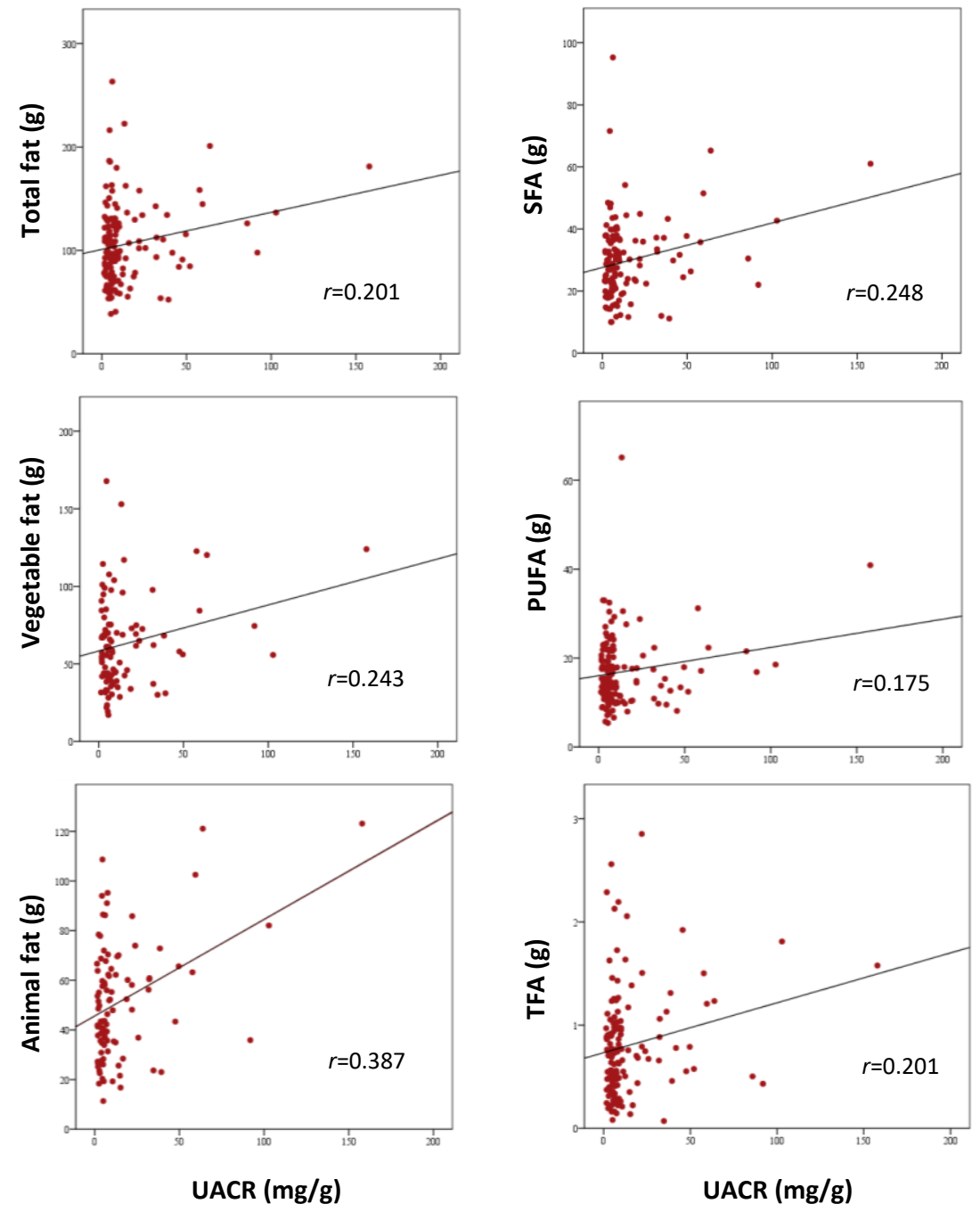

Figure 1. Pearson's correlation analysis between UACR and dietary fats (all $p<0.05)$. Abbreviations: PUFA: polyunsaturated fatty acids; SFA: saturated fatty acids; TFA: trans fatty acids; UACR: urine albumin-to-creatinine ratio.

\section{Discussion}

In the current study, dietary fat from animal sources was significantly associated with increased UACR. The association was independent of mean caloric intake, gender, age, smoking, alcohol consumption, physical activity, and use of ACEi or ARBs. Consistently, consumption of animal fat was higher in patients with moderately increased albuminuria compared to those with normal albuminuria.

In genetic and non-genetic animal models of MetS, consumption of a high-fat diet of mainly animal sources significantly altered the kidney structure and function, inducing increased albuminuria, renal injury, and inflammation, when compared to rats fed a low-fat diet [39-41]. Moreover, when quantity of feeding and fat was restricted, further alterations at kidney level were prevented [39]. On the other hand, consumption of unsaturated fats from vegetable sources improved albuminuria, inflammation, and extracellular matrix synthesis in diabetic rats as compared to placebo [42]. At renal level, it was observed that a diet rich in animal fat accelerated renal lipogenesis and suppressed renal lipolysis, with a subsequent accumulation of fat (mainly triglycerides) in both the glomerular and proximal tubules $[39,40,43]$. In an abnormally metabolic state, excess lipid accumulation in the kidney led to the disruption of the structural integrity of the glomerulus [39,40], induced macrophage infiltration, impaired sodium handling, and increased expression of renin and angiotensinogen [39] and promoted mitochondrial disfunction and, thus, 
increased oxidative stress and inflammation [43]. In humans, whether lipid accumulation in the kidney is always an etiological factor in the development of glomerular hypertrophy is unknown; however, renal biopsy tissues from patients with T2DM and obesity-related glomerulopathy showed increased lipid deposits in mesangial cells, podocytes, and proximal tubular cells, and most importantly, the extent of the accumulation was proportional to UACR, renal injury, inflammation, and metabolic state [44,45].

Population-based studies observe an association between fat intake, and especially saturated fat, and albuminuria. Specifically, a study on women between the age of 30 and 55 found an odds ratio (OR) of 1.72 (95\% confidence interval (CI): 1.12-2.64) when comparing the lowest with the highest quartile of animal fat intake, and an OR of 1.51 (95\% CI: 1.01-2.26) when consuming two or more servings/week of red meat for the risk of increased albuminuria [30]. Another cross-sectional study investigating the association between animal fat and early kidney disease in 19,256 participants aged 45 years and older found that saturated fat intake was the only type of fat significantly associated with the presence of high albuminuria (for quintile 5 compared with quintile 1, OR: $1.33 ; 95 \%$ CI: 1.07-1.66) [31]. To the best of our knowledge, no other published data are available on the relation between animal fat intake and albuminuria in the general adult population, and no studies are available in subjects with MetS and NAFLD. Nevertheless, all together, these consistent observations corroborate the hypothesis that dietary fat from animal sources may play a role in the development of albuminuria, and possibly more so when important risk factors such as MetS and NAFLD are already present.

Unfortunately, our data on animal fat could not differentiate between fat from meat and fat from fish. Some studies on protein sources suggest that fish proteins do not affect albuminuria as much as proteins from meat and meat products $[28,46]$, and the same could be true for fat. Several studies on omega-3 polyunsaturated FA supplementation report beneficial effects on urinary albumin excretion and kidney function in patients with and without diabetes [47-50], possibly by decreasing inflammation and endothelial dysfunction, as well as reducing hypertension and dyslipidemia [51].

Of note, about one third of patients were receiving renin-angiotensin system inhibitor therapy, and it could be speculated that in those patients the detrimental effect of increased animal fat consumption on UACR could be curbed by the renoprotective properties of the therapy [52]. Nevertheless, in multivariate analysis, the relationship between animal fat intake and UACR was independent of ACEi or ABRs therapy.

\section{Strengths and Limitations}

The main limitation of the study is that it was not designed to specifically look at predictors of UACR. Hence, patients were not included according to different stages of $\mathrm{UACR}$, and the vast majority presented levels within the normal range. In fact, only 20 cases presented increased albuminuria. This could explain the weak association, although significant, between UACR and dietary fats. Another limitation is the limited number of patients: a bigger sample could give a more confident answer to the possible relationship between type of fat and the development of increased albuminuria.

\section{Conclusions}

In the current study of patients with MetS and NAFLD, but free of CVD and CKD, consumption of fat from animal sources was associated with increasing levels of albuminuria, independently of mean energy intake and other possible confounding factors. Increased albuminuria is a risk factor for both CKD and CVD, which in turn, weigh heavily on the economic resources of households, health systems, and society [53]. Despite the study's limitation, these results point out that something as simple as dietary choices could indirectly contribute to the burden.

Patients with MetS and NAFLD are exposed to an increased incidence of a variety of clinical conditions, which could worsen to serious health implications as they manifest and coexist. Besides early screening and appropriate care, it is also fundamental to raise 
awareness about the effects of dietary choices in the development of chronic diseases. Large intervention studies with prospective dietary measures are needed to elucidate the role of diet in the possible modification of renal vascular dysfunction as an early CVD predictor in patients with metabolic syndrome.

Author Contributions: Conceptualization, M.A., J.A.M. and J.A.T.; Data curation, M.A., C.M.M., S.M., M.B.-L. and J.A.T.; Formal analysis, M.A., M.B.-L. and J.A.T.; Funding acquisition, J.A.T.; Investigation, M.A., C.M.M., S.M., M.B.-L., M.C., C.G., L.U., S.T., I.A., M.Á.Z., A.S., J.A.M. and J.A.T.; Project administration, J.A.T.; Supervision, J.A.T.; Writing—original draft, M.A., J.A.M. and J.A.T.; Writing—review \& editing, M.A., C.M.M., S.M., M.B.-L., M.C., C.G., L.U., S.T., I.A., M.Á.Z., A.S., J.A.M. and J.A.T. All authors have read and agreed to the published version of the manuscript.

Funding: This research was funded by Fundació La Marató TV3 (Spain) project ref. 201630.10. Instituto de Salud Carlos III through the Fondo de Investigación para la Salud (Projects PI14/00636 and PI17/01827, CIBEROBN CB12/03/30038, and Proyecto Intramural CIBER OBN18PI03), Health Department of the Government of Navarra (61/2015), and Grant of support to research groups no. 35/2011 and 23/2012 (Balearic Islands Government), which are co-funded by the European Regional Development Fund. Other funding received: EU-COST Action CA16112, and IDISBA Grants (FOLIUM, PRIMUS, SYNERGIA, and LIBERI). Catalina M. Mascaró received an FPU PhD Grant from the Spanish Ministry of Education. The funding sponsors had no role in the design of the study, in the collection, analyses, or interpretation of the data; in the writing of the manuscript, or in the decision to publish the results.

Institutional Review Board Statement: The study was conducted according to the guidelines of the Declaration of Helsinki and approved by the Ethics Committee of the Balearic Islands (ref. IB 2251/14 PI) and the Ethics Committee of the University of Navarra (ref. 054/2015mod2).

Informed Consent Statement: Informed consent was obtained from all subjects involved in the study. Written informed consent has been obtained from the patient(s) to publish this paper if applicable.

Data Availability Statement: There are restrictions on the availability of data for this trial, due to the signed consent agreements around data sharing, which only allow access to external researchers for studies following the project purposes. Requestors wishing to access the trial data used in this study can make a request to pep.tur@uib.es.

Acknowledgments: The authors especially thank the participants for their enthusiastic collaboration, the personnel for outstanding support, and exceptional effort. The authors thank Octavio Barbero from Red Asistencial Juaneda, Palma de Mallorca, Spain, for technical assistance. CIBEROBN is an initiative of Instituto de Salud Carlos III, Spain.

Conflicts of Interest: The authors declare no conflict of interest.

\section{References}

1. Ng, W.Y.; Lui, K.F.; Thai, A.C. Evaluation of a rapid screening test for microalbuminuria with a spot measurement of urine albumin-creatinine ratio. Ann. Acad. Med. Singap. 2000, 29, 62-65.

2. Chugh, A.; Bakris, G.L. Microalbuminuria: What is it? Why is it important? What should be done about it? An update. J. Clin. Hypertens. 2007, 9, 196-200. [CrossRef]

3. Weir, M.R. Microalbuminuria and Cardiovascular Disease. Clin. J. Am. Soc. Nephrol. 2007, 2, 581-590. [CrossRef]

4. Romundstad, S.; Holmen, J.; Kvenild, K.; Hallan, H.; Ellekjær, H. Microalbuminuria and all-cause mortality in 2089 apparently healthy individuals: A 4.4-year follow-up study. The Nord-Trøndelag Health Study (HUNT), Norway. Am. J. Kidney Dis. 2003, 42, 466-473. [CrossRef]

5. Hoehner, C.M.; Greenlund, K.J.; Rith-Najarian, S.; Casper, M.L.; McClellan, W.M. Association of the Insulin Resistance Syndrome and Microalbuminuria among Nondiabetic Native Americans. The Inter-Tribal Heart Project. J. Am. Soc. Nephrol. 2002, 13, 1626-1634. [CrossRef]

6. Rachmani, R.; Levi, Z.; Lidar, M.; Slavachevski, I.; Half-Onn, E.; Ravid, M. Considerations about the threshold value of microalbuminuria in patients with diabetes mellitus: Lessons from an 8-year follow-up study of 599 patients. Diabetes Res. Clin. Pract. 2000, 49, 187-194. [CrossRef]

7. Arnlöv, J.; Evans, J.C.; Meigs, J.B.; Wang, T.J.; Fox, C.S.; Levy, D.; Benjamin, E.J.; D’Agostino, R.B.; Vasan, R.S. Low-grade albuminuria and incidence of cardiovascular disease events in nonhypertensive and nondiabetic individuals: The Framingham Heart Study. Circulation 2005, 112, 969-975. [CrossRef] [PubMed] 
8. Matsushita, K.; Van Der Velde, M.; Astor, B.C.; Woodward, M.; Levey, A.S.; De Jong, P.E.; Coresh, J.; Gansevoort, R.T. Association of estimated glomerular filtration rate and albuminuria with all-cause and cardiovascular mortality in general population cohorts: A collaborative meta-analysis. Lancet 2010, 375, 2073-2081. [CrossRef] [PubMed]

9. Kim, C.H.; Younossi, Z.M. Nonalcoholic fatty liver disease: A manifestation of the metabolic syndrome. Clevel. Clin. J. Med. 2008, 75, 721-728. [CrossRef]

10. Stepanova, M.; Rafiq, N.; Makhlouf, H.; Agrawal, R.; Kaur, I.; Younoszai, Z.; McCullough, A.; Goodman, Z.; Younossi, Z.M. Predictors of All-Cause Mortality and Liver-Related Mortality in Patients with Non-Alcoholic Fatty Liver Disease (NAFLD). Dig. Dis. Sci. 2013, 58, 3017-3023. [CrossRef]

11. Ekstedt, M.; Hagström, H.; Nasr, P.; Fredrikson, M.; Stål, P.; Kechagias, S.; Hultcrantz, R. Fibrosis stage is the strongest predictor for disease-specific mortality in NAFLD after up to 33 years of follow-up. Hepatology 2015, 61, 1547-1554. [CrossRef] [PubMed]

12. Younossi, Z.M.; Otgonsuren, M.; Venkatesan, C.; Mishra, A. In patients with non-alcoholic fatty liver disease, meta-bolically abnormal individuals are at a higher risk for mortality while metabolically normal individuals are not. Me-Tabolism 2013, 62, 352-360.

13. Lin, L.; Lu, J.; Huang, X.; Ding, L.; Huang, Y.; Wang, P.; Peng, K.; Zhang, D.; Xu, Y.; Xu, M.; et al. Nonalcoholic fatty liver disease is associated with low-grade albuminuria in Chinese adults (change not displayed). QJM Int. J. Med. 2016, 109, 737-743. [CrossRef]

14. Kang, S.H.; Cho, K.H.; Do, J.Y. Non-alcoholic fatty liver disease is associated with low-grade albuminuria in men without diabetes mellitus. Int. J. Med. Sci. 2019, 16, 285-291. [CrossRef] [PubMed]

15. Amin, R.F.; El Bendary, A.S.; Ezzat, S.E.; Mohamed, W.S. Serum Ferritin level, microalbuminuria and non-alcoholic fatty liver disease in type 2 diabetic patients. Diabetes Metab. Syndr. Clin. Res. Rev. 2019, 13, 2226-2229. [CrossRef] [PubMed]

16. Chang, A.; Van Horn, L.; Jacobs, D.R., Jr.; Liu, K.; Muntner, P.; Newsome, B.; Shoham, D.A.; Durazo-Arvizu, R.; Bib-binsDomingo, K.; Reis, J.; et al. Lifestyle-related factors, obesity, and incident microalbuminuria: The CARDIA (Cor-onary Artery Risk Development in Young Adults) study. Am. J. Kidney Dis. 2013, 62, 267-275. [CrossRef]

17. Guo, V.Y.; Brage, S.; Ekelund, U.M.; Griffin, S.J.; Simmons, R.K.; Amin, R.; Baker, G.; Betts, M.; Dickinson, A.; Tcheugui, J.B.E.; et al. Objectively measured sedentary time, physical activity and kidney function in people with recently diagnosed Type 2 diabetes: A prospective cohort analysis. Diabet. Med. 2015, 33, 1222-1229. [CrossRef] [PubMed]

18. Lynch, B.M.; White, S.L.; Owen, N.; Healy, G.N.; Chadban, S.J.; Atkins, R.C.; Dunstan, D.W. Television Viewing Time and Risk of Chronic Kidney Disease in Adults: The AusDiab Study. Ann. Behav. Med. 2010, 40, 265-274. [CrossRef]

19. Nettleton, J.A.; Steffen, L.M.; Palmas, W.; Burke, G.L.; Jacobs, D.R. Associations between microalbuminuria and animal foods, plant foods, and dietary patterns in the Multiethnic Study of Atherosclerosis. Am. J. Clin. Nutr. 2008, 87, 1825-1836. [CrossRef]

20. Agrawal, V.; Khan, I.; Rai, B.; Krause, K.; Chengelis, D.; Zalesin, K.; Rocher, L.; McCullough, P. The effect of weight loss after bariatric surgery on albuminuria. Clin. Nephrol. 2008, 70, 194-202. [CrossRef]

21. Praga, M.; Morales, E. Weight Loss and Proteinuria. Contrib. Nephrol. 2006, 151, 221-229. [CrossRef]

22. Ruggenenti, P.; Abbate, M.; Ruggiero, B.; Rota, S.; Trillini, M.; Aparicio, C.; Parvanova, A.; Petrov Iliev, I.; Pisanu, G.; Perna, A.; et al. Renal and Systemic Effects of Calorie Restriction in Patients With Type 2 Diabetes With Abdominal Obesity: A Randomized Controlled Trial. Diabetes 2016, 66, 75-86. [CrossRef] [PubMed]

23. Hansen, H.P.; Christensen, P.K.; Tauber-Lassen, E.; Klausen, A.; Jensen, B.R.; Parving, H.-H. Low-protein diet and kidney function in insulin-dependent diabetic patients with diabetic nephropathy. Kidney Int. 1999, 55, 621-628. [CrossRef] [PubMed]

24. Schaap, G.H.; Bilo, H.J.; Alferink, T.H.; Oe, P.L.; Donker, A.J. The effect of a high protein intake on renal function of pa-tients with chronic renal insufficiency. Nephron 1987, 47, 1-6. [CrossRef]

25. Hoogeveen, E.K.; Kostense, P.J.; Jager, A.; Heine, R.J.; Jakobs, C.; Bouter, L.M.; Donker, A.J.; Stehouwer, C.D. Serum homocysteine level and protein intake are related to risk of microalbuminuria: The Hoorn Study. Kidney Int. 1998, 54, 203-209. [CrossRef]

26. Toeller, M.; Buyken, A.; Heitkamp, G.; Brmswig, S.; Mann, J.; Milneet, R.; Gries, F.A.; Keen, H. Protein intake and urinary albumin excretion rates in the EURODIABIDDM Complications Study. Diabetologia 1997, 40, 1219-1226. [CrossRef]

27. Wrone, E.M.; Carnethon, M.R.; Palaniappan, L.; Fortmann, S.P. Association of dietary protein intake and microalbu-minuria in healthy adults: Third National Health and Nutrition Examination Survey. Am. J. Kidney Dis. 2003, 41, 580-587. [CrossRef] [PubMed]

28. Bernstein, A.M.; Treyzon, L.; Li, Z. Are High-Protein, Vegetable-Based Diets Safe for Kidney Function? A Review of the Literature. J. Am. Diet. Assoc. 2007, 107, 644-650. [CrossRef]

29. Wheeler, M.L.; Fineberg, S.E.; Fineberg, N.S.; Gibson, R.G.; Hackward, L.L. Animal Versus Plant Protein Meals in Indi-viduals With Type 2 Diabetes and Microalbuminuria. Diabetes Care 2002, 25, 1277-1282. [CrossRef]

30. Lin, J.; Hu, F.B.; Curhan, G.C. Associations of Diet with Albuminuria and Kidney Function Decline. Clin. J. Am. Soc. Nephrol. 2010, 5, 836-843. [CrossRef]

31. Lin, J.; Judd, S.; Le, A.; Ard, J.; Newsome, B.B.; Howard, G.; Warnock, D.G.; McClellan, W. Associations of dietary fat with albuminuria and kidney dysfunction. Am. J. Clin. Nutr. 2010, 92, 897-904. [CrossRef]

32. The International Diabetic Federation (IDF). The IDF Consensus Worldwide Definition of the Metabolic Syndrome. Available online: http:/ / www.idf.org/webdata/docs/IDF_Meta_def_final.pdf (accessed on 7 May 2020).

33. Elosua, R.; Marrugat, J.; Molina, L.; Pons, S.; Pujol, E. Validation of the Minnesota Leisure Time Physical Activity Ques-tionnaire in Spanish Men. Am. J. Epidemiol. 1994, 139, 1197-1209. [CrossRef] 
34. Elosua, R.; Garcia, M.; Aguilar, A.; Molina, L.; Covas, M.I.; Marrugat, J. Validation of the Minnesota Leisure Time Physical Activity Questionnaire in Spanish Women. Med. Sci. Sports Exerc. 2000, 32, 1431-1437. [CrossRef] [PubMed]

35. Willett, W.C.; Sampson, L.; Stampfer, M.J.; Rosner, B.; Bain, C.; Witschi, J.; Hennekens, C.H.; Speizer, F.E. Reproducibility and Validity of a Semiquantitative Food Frequency Questionnaire. Am. J. Epidemiol. 1985, 122, 51-65. [CrossRef]

36. Friedewald, W.T.; Levy, R.I.; Fredrickson, D.S. Estimation of the Concentration of Low-Density Lipoprotein Cholesterol in Plasma, Without Use of the Preparative Ultracentrifuge. Clin. Chem. 1972, 18, 499-502. [CrossRef]

37. Matthews, D.R.; Hosker, J.P.; Rudenski, A.S.; Naylor, B.A.; Treacher, D.F.; Turner, R.C. Homeostasis model assessment: Insulin resistance and beta-cell function from fasting plasma glucose and insulin concentrations in man. Diabetologia 1985, 28, 412-419. [CrossRef] [PubMed]

38. Levey, A.S.; Coresh, J.; Greene, T.; Stevens, L.A.; Zhang, Y.L.; Hendriksen, S.; Kusek, J.W.; Van Lente, F. Chronic Kidney Disease Epidemiology Collaboration. Using Standardized Serum Creatinine Values in the Modification of Diet in Renal Disease Study Equation for Estimating Glomerular Filtration Rate. Ann. Intern. Med. 2006, 145, 247-254. [CrossRef] [PubMed]

39. Deji, N.; Kume, S.; Araki, S.-I.; Soumura, M.; Sugimoto, T.; Isshiki, K.; Chin-Kanasaki, M.; Sakaguchi, M.; Koya, D.; Haneda, M.; et al. Structural and functional changes in the kidneys of high-fat diet-induced obese mice. Am. J. Physiol. Physiol. 2009, 296, F118-F126. [CrossRef] [PubMed]

40. Kume, S.; Uzu, T.; Araki, S.-I.; Sugimoto, T.; Isshiki, K.; Chin-Kanasaki, M.; Sakaguchi, M.; Kubota, N.; Terauchi, Y.; Kadowaki, T.; et al. Role of Altered Renal Lipid Metabolism in the Development of Renal Injury Induced by a High-Fat Diet. J. Am. Soc. Nephrol. 2007, 18, 2715-2723. [CrossRef] [PubMed]

41. Tokuyama, H.; Wakino, S.; Hara, Y.; Washida, N.; Fujimura, K.; Hosoya, K.; Yoshioka, K.; Hasegawa, K.; Minakuchi, H.; Homma, K.; et al. Role of mineralocorticoid receptor/Rho/Rho-kinase pathway in obesity-related renal injury. Int. J. Obes. 2011, 36, 1062-1071. [CrossRef] [PubMed]

42. Kim, D.-H.; Yoo, T.-H.; Lee, S.H.; Kang, H.Y.; Nam, B.Y.; Kwak, S.J.; Kim, J.-K.; Park, J.T.; Han, S.H.; Kang, S.-W. Gamma Linolenic Acid Exerts Anti-Inflammatory and Anti-Fibrotic Effects in Diabetic Nephropathy. Yonsei Med. J. 2012, 53, 1165-1175. [CrossRef]

43. Sun, Y.; Ge, X.; Li, X.; He, J.; Wei, X.; Du, J.; Sun, J.; Li, X.; Xun, Z.; Liu, W.; et al. High-fat diet promotes renal injury by inducing oxidative stress and mitochondrial dysfunction. Cell Death Dis. 2020, 11, 1-14. [CrossRef]

44. de Vries, A.P.J.; Ruggenenti, P.; Ruan, X.Z.; Praga, M.; Cruzado, J.M.; Bajema, I.M.; D'Agati, V.D.; Lamb, H.J.; Barlovic, D.P.; Hojs, R.; et al. Fatty kidney: Emerging role of ectopic lipid in obesity-related renal disease. Lancet Diabetes Endocrinol. 2014, 2, 417-426. [CrossRef]

45. Yang, W.; Luo, Y.; Yang, S.; Zeng, M.; Zhang, S.; Liu, J.; Han, Y.; Liu, Y.; Zhu, X.; Wu, H.; et al. Ectopic lipid accumulation: Potential role in tubular injury and inflammation in diabetic kidney disease. Clin. Sci. 2018, 132, 2407-2422. [CrossRef] [PubMed]

46. Möllsten, A.V.; Dahlquist, G.G.; Stattin, E.-L.; Rudberg, S. Higher intakes of fish protein are related to a lower risk of microalbuminuria in young Swedish type 1 diabetic patients. Diabetes Care 2001, 24, 805-810. [CrossRef] [PubMed]

47. Jensen, T.; Stender, S.; Goldstein, K.; Hølmer, G.; Deckert, T. Partial Normalization by Dietary Cod-Liver Oil of Increased Microvascular Albumin Leakage in Patients with Insulin-Dependent Diabetes and Albuminuria. N. Engl. J. Med. 1989, 321, 1572-1577. [CrossRef]

48. Rossing, P.; Hansen, B.V.; Nielsen, F.S.; Myrup, B.; Hølmer, G.; Parving, H.-H. Fish Oil in Diabetic Nephropathy. Diabetes Care 1996, 19, 1214-1219. [CrossRef] [PubMed]

49. Hu, J.; Liu, Z.; Zhang, H. Omega-3 fatty acid supplementation as an adjunctive therapy in the treatment of chronic kidney disease: A meta-analysis. Clinics 2017, 72, 58-64. [CrossRef]

50. Pei, K.; Gui, T.; Li, C.; Zhang, Q.; Feng, H.; Li, Y.; Wu, J.; Gai, Z. Recent Progress on Lipid Intake and Chronic Kidney Disease. BioMed Res. Int. 2020, 2020, 1-11. [CrossRef]

51. Shapiro, H.; Theilla, M.; Attal-Singer, J.; Singer, P. Effects of polyunsaturated fatty acid consumption in diabetic nephropathy. Nat. Rev. Nephrol. 2010, 7, 110-121. [CrossRef] [PubMed]

52. Stevens, P.E.; Levin, A. Kidney Disease: Improving Global Outcomes Chronic Kidney Disease Guideline Development Work Group Members. Evaluation and management of chronic kidney disease: Synopsis of the kidney disease: Im-proving global outcomes 2012 clinical practice guideline. Ann. Intern. Med. 2013, 158, 825-830. [CrossRef] [PubMed]

53. Gheorghe, A.; Griffiths, U.; Murphy, A.; Legido-Quigley, H.; Lamptey, P.; Perel, P. The economic burden of cardiovascular disease and hypertension in low- and middle-income countries: A systematic review. BMC Public Health 2018, 18, 1-11. [CrossRef] [PubMed] 